\title{
Becoming an Associate Dean: A Librarian's Tale of Lessons Learned By Mary Ann Venner
}

Leadership roles present unique opportunities to learn new skills, to develop better ways of engagement and to lead teams in a positive, innovative direction. Transitioning from a faculty role to an administrative one creates a landscape of learning that promotes growth and exposes challenges. The lessons learned from these experiences promote leadership development that strengthens decision making, problem solving and strategic planning. As a librarian who once served as a faculty member but then became an Associate Dean, the leadership lessons learned have been tremendously beneficial.

\section{Communication}

Being an effective communicator is one of the most important skills an Associate Dean should have. Lack of communication can create poor morale, cause misunderstandings and leave faculty and staff feeling disconnected to the organization. Good communicators:

- Are present and engaged

- Ask the right questions

- Keep an open mind and listen to all sides

- Value feedback and provide avenues to gather it

- Are honest and transparent

- Communicate the why's of change

- Present a clear vision

- Provide clear expectations

- Are professional and respectful in all communications

Sharing out information that can be shared in a timely manner is also important. Adapting these characteristics to a leadership style helps leaders create an environment that is positive.

\section{Positive Leadership}

Setting an example of positive leadership is one of the best ways to motivate others to be solution oriented instead of focusing on the negative aspects of a situation for too long. Elements of positive leadership include:

- Acknowledging when there is a problem and listening to the concerns

- Presenting options and solutions

- Leading by example

- Not being reactionary

- Building consensus

- Setting a good work/life balance

- Being open to change

- Approaching meetings with a good and respectful attitude

- Being an empathetic listener

- Saying hello and checking in

- Celebrating successes and giving recognition for a job well done 
- Promoting team building and collaboration

Positive leaders have the ability to guide others through times of change more effectively because of the foundational structures they set for their teams. Creating a positive environment which is respectful of differing opinions and focuses on finding solutions is good for morale and encourages others to contribute ideas and provide feedback.

\section{Skill development}

As a new Associate Dean, the increased level of responsibility presents its own challenges. Skill development and training are helpful ways to adapt to new areas of learning, but it does take some time so patience and a willingness to learn are necessary. Strategic planning, operational planning, budgeting, allocating resources, and personnel management are just a few of these areas. Ways to increase skill development include:

- Identifying areas to develop

- Setting a professional and skill development plan

- Finding a group of leadership peers and mentors

- Attending training sessions in targeted areas

- Collaborating with other campus areas

- Attending conferences focused on leadership development

- Reading the latest issues of leadership publications

- Not being afraid to ask questions

- Participating in opportunities outside of your comfort zone

Another way to develop your skills as an administrative leader is to have a good working relationship with your Dean. Meetings with the Dean provide opportunities to learn how to problem solve, discuss leadership challenges, look at big picture goal setting and develop effective partnerships.

\section{Collaboration}

For an Associate Dean creating opportunities for collaboration are ways to become more connected to what is happening on campus and promote innovative partnerships. Some of the most successful collaborations arise from serendipitous meetings and chance encounters at campus events, conferences and workshops. It is also important to create an environment for collaboration within an organization. Ways to promote collaboration include encouraging faculty to:

- Attend campus events and outreach activities

- Stay abreast of changes on campus, new faculty research areas and newly created departments

- Find mentors outside their discipline

- Participate in Faculty Senate and campus committees

- Connect with other university peers

Collaborations across campus help areas such as academic libraries become more involved in discussions on student success, student retention, faculty development, and faculty research support.

Delegating 
Delegating is a skill that some leaders excel at while others fail to utilize. Delegating can be one of the most difficult things to do for a variety of reasons. Sometimes it seems easier to follow through with a project rather than assign it to someone else. There may be a concern that the person the task is delegated to will not complete it well. Delegating tasks and projects to others in the right way, however, provides a multitude of benefits such as:

- Empowering others to learn a new area and take on new responsibilities

- Freeing up time to focus on other areas

- Utilizing the strengths of your team more effectively

- Building trust

- Encouraging professional development

Associate Deans who do not delegate tasks effectively can become overwhelmed and reach a level of burnout very quickly. Effective time management includes the ability to delegate projects and tasks where needed so established deadlines can be met and goals can be achieved through a team approach.

Pitfalls

Leadership pitfalls are often unforeseen and difficult to overcome if not addressed quickly. They can present themselves in several areas. Examples of these pitfalls include:

- Making assumptions

- Not allocating resources efficiently

- Not setting expectations clearly

- Being reactionary

- Being late or not prepared for meetings

- Delegating too much or too little

- Not communicating effectively

- Not creating avenues for feedback

- Not being open to change or new ideas

- Not listening to all sides of an issue

Helpful ways to avoid these pitfalls include good communications with faculty and reflecting on constructive criticisms received in administrator evaluations and surveys in a timely manner. Feedback from direct reports can help identify problem areas to address before they become bigger issues. Facilitating department retreats to discuss areas such as goal planning, managing change and promoting teamwork and good communication are helpful ways to proactively minimize falling into leadership pitfalls. Doing self- evaluations and reflecting on decisions that have been made are additional ways to recognize areas of improvement.

\section{Conclusion}

Becoming an Associate Dean opens a whole new world of possibilities in terms of leadership development. Once a faculty member becomes an Associate Dean there are several adjustments to their levels of responsibility. Much of their time becomes more focused on administrative duties and the responsibilities associated with them. Focusing on ways to improve communication, positive leadership, skill development, collaboration and delegating enable administrators to lead their teams more 
effectively. Recognizing the paths to leadership pitfalls before they occur is a skill that comes with experience and learning. Developing a network of peers to discuss professional development and management tips is very helpful.

Being an Associate Dean is one of the most rewarding roles a faculty member can grow into. Although the role may present its own unique set of challenges, the opportunities it also presents in terms of leadership growth, faculty and staff engagement and vision building are numerous. For a librarian the role is a great way to build upon their learning experiences and perspectives as a faculty member. Their interactions with students and other faculty members only enhance their leadership toolkit and enable better decision making as more perspectives are considered.

Mary Ann Venner is the Associate Dean for Public Services at the University of North Texas Libraries. Email: maryann.venner@unt.edu 